\title{
Endosonographic features of rectal cancer: A single-center experience in Iran
}

\author{
Mojgan Frootan, Ainaz Sourati ${ }^{1}$, Morteza Tabatabaeefar ${ }^{1}$, Mohammad Reza Nikshoar ${ }^{2}$, \\ Ali Mohammad Faizei ${ }^{3}$
}

Departments of Gastroenterology, ${ }^{1}$ Radiotherapy, ${ }^{2}$ Surgery and ${ }^{3}$ Radiology, Emam Hossein Hospital, Shahid Beheshti University of Medical Sciences, Tehran, Iran

Abstract
Context: Colorectal cancer is the fourth leading cause of cancer death worldwide.
Aim: The study aim was to describe an endosonographic feature of rectal cancer in Iranian
patients. Settings and Design: A retrospective study in Mehrad Hospital, Tehran, Iran.
Materials and Methods: In this case series, all patients with confirmed diagnosis of rectal cancer
during $2012-2014$ were included and their hospital records were reviewed. Results: Hospital
records of 76 patients with rectal cancer including 44 male $(57.9 \%)$ and 32 females $(42.1 \%)$
were reviewed. The mean age of patients was $57.81 \pm 14.26$ years. The distal rectum was the
most common location of the tumor (42 patients, $55.3 \%)$ and complete luminal obstruction
was observed in 11 patients (14.5\%). Sphincters were free of disease in $70 \%$ of patients (53),
while lymph nodes were involved in more than $70 \%$ of patients at diagnosis. Internal anal
sphincter (IAS) alone was the most common sphincter involved (16 patients, $21 \%$ ) followed by
involvement of all three sphincters together (IAS and external anal sphincter and longitudinal
muscle) (5, $6.6 \%)$. Conclusion: The mean age at diagnosis of rectal cancer in our country is
less than that of Western countries. Lower rectum is the most common location of rectal
cancer in our patients and lymph node metastasis is present in more than $70 \%$ of patients at
the time of diagnosis.
Colorectal cancer, endosonography, malignancy
Key words

\section{Introduction}

Colorectal cancer (CRC) is the most common malignancy in the gastrointestinal tract. CRC is the third most common form of cancer and the fourth leading cause of cancer death worldwide. ${ }^{[1]}$ The incidence of CRC was estimated 1.36 million with 694,000 deaths by the World Health Organization (WHO) in 2012 worldwide. According to the same report, CRC is the third most common cancer among men ( $10 \%$ of all cancers) and the second in women ( $9.2 \%$ of the total). The incidence

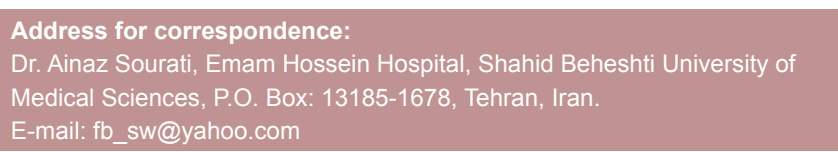

\begin{tabular}{|l|c|}
\hline \multicolumn{2}{|c|}{ Access this article online } \\
\hline \multirow{2}{*}{$\begin{array}{l}\text { Website: } \\
\text { www.jdeonline.in }\end{array}$} & Quick Response Code \\
\hline DOI: & \\
10.4103/0976-5042.180087 & \\
&
\end{tabular}

rate and mortality of CRC are similar in men and women although a bit is higher among men. ${ }^{[1]}$ According to the WHO report 2012, CRC incidence and mortality in the East Mediterranean Regional Office (EMRO) is significantly lower than the Americas and Europe areas. ${ }^{[1]}$ While the trend of CRC incidence over the past decade in less developed regions has been growing, at the same time it has been descending in more developed areas. The figure for CRC mortality trend in the same period in the world has been the same of incidence trend. ${ }^{[1]}$

In Iran as a country of EMRO, CRC is the third frequent cancer among women and fifth in men. ${ }^{[2]}$ According to a recent study, although the incidence of CRC is low in Iran, its trends has been a slightly increasing in recent years. ${ }^{[2,3]}$

This is an open access article distributed under the terms of the Creative Commons Attribution-NonCommercial-ShareAlike 3.0 License, which allows others to remix, tweak, and build upon the work non-commercially, as long as the author is credited and the new creations are licensed under the identical terms.

For reprints contact: reprints@medknow.com

How to cite this article: Frootan M, Sourati A, Tabatabaeefar M, Nikshoar MR, Faizei AM. Endosonographic features of rectal cancer: A single-center experience in Iran. J Dig Endosc 2016;7:11-4. 
CRCs are classified according to the International Classification of Diseases for Oncology to colon or rectum cancers. ${ }^{[4]}$ Rectum is the second most common location of CRCs (28\%) after proximal colon ( $42 \%$ ) and about one-third of CRC occur in rectum. ${ }^{[5,6]}$ The incidence of rectal cancer in contrast to the proximal colon cancers, in men is slightly higher than the women (31\% vs. $24 \%$ ). ${ }^{[5]}$ During a decade from 2001 to 2010 , the incidence rate of rectal cancer has decreased in adults aged 65 and older while it has increased $1.8 \%$ annually in those younger than 50 years. ${ }^{[5]}$ It has been estimated that incidence of rectal cancer to increase by $124.2 \%$ for patients aged $20-34$ years by $2030 .{ }^{[6]}$

Overall 5-year survival for rectal cancer (66.5\%) has been reported to be a slightly higher than for colon cancer $(64.2 \%) .{ }^{[5]}$ The survival rate is not significantly different between men and women while overall mortality rate is $30-40 \%$ higher in men than in women although it differs by age. ${ }^{[5]}$

This study aim was to report endosonographic features of rectal cancer at diagnosis in Iranian patients.

\section{Materials and Methods}

This retrospective case series was conducted during a 3-year period (2012-2014) in Mehrad Hospital, Tehran, Iran. Hospital records of all patients referred to gastroenterology clinic at Mehrad Hospital during the study period and were newly diagnosed with rectal carcinoma were reviewed. Only new cases with confirmed diagnosis of rectal carcinoma were included in the study and those with known history of rectal carcinoma were excluded. Data about endosonographic features of rectal cancer were collected from hospital file of patients. Tumor characteristics were determined in all patients with endosonography.

The study protocol was approved by the Ethics Committee at Mehrad Hospital.

\section{Statistical analysis}

Obtained data were analyzed using SPSS software version 17.00 for Windows (SPSS Inc., Chicago, IL, USA) for Windows. Data are presented as a mean \pm standard deviation for numerical data and number and percentage for categorical data. Descriptive statistics and independent sample descriptive statistics and $t$-test were used for data analysis. $P \leq 0.05$ was considered as a significance level.

\section{Results}

The study included 76 patients with rectal cancer including 44 male (57.9\%) and 32 (42.1\%) females. The mean age of patients was $57.81 \pm 14.26$ years. Although the mean age of men was lower than in the women, the difference was not significant (54.92 years vs. 61.67 years) $(P=0.29)$. Median age at diagnosis was 56 years and it was higher in men than in the women ( 57 years in men vs. 56 years in women). The age of most patients in our study was between 50 and 65 years $(52.4 \%)$ and they were in middle age.

Tumor size in $65.8 \%$ (50) of patients was in T3 stage, in 19.7\% (15) in $\mathrm{T} 2$, in $10.5 \%$ (8) in $\mathrm{T} 1$, and in $3.1 \%$ (4) was in $\mathrm{T} 4$ stage. Regarding lymph node involvement, 21 patients $(27.6 \%)$ had no lymph node involvement, $53.9 \%$ of patients (41) were in N1 stage, $11.8 \%$ (9) patients in N2, and $5.3 \%$ (4) were in N3 stage.

Tumor was located in the distal part of rectum in $55.3 \%$ of patients (42), in the middle part in 26 patients $(34.2 \%)$ and in proximal part in 8 patients $(10.5 \%)$. Rectal tumor caused complete luminal obstruction in 11 patients (14.5\%) and partial obstruction in $64(84.2 \%)$ patients.

Mean tumor distance from anal verge at diagnosis was $6.94 \pm 3.64 \mathrm{~cm}(1-18 \mathrm{~cm})$. Tumor distance from anal verge was $<6 \mathrm{~cm}$ in 42 patients $(55.3 \%), 7-11 \mathrm{~cm}$ in 25 patients $(32.9 \%)$, $12-15 \mathrm{~cm}$ in 6 patients $(7.9 \%)$, and more than $15 \mathrm{~cm}$ in $3.9 \%$ (3) of patients. Tumor distance from anal verge was not significantly different between males and females $(P=0.65)$.

No case of bladder, seminal vesicle, and urethra involvement was observed in the patients. Prostate involvement was found in three men while uterine involvement was not seen in women.

Seventy percent of patients (53) had no sphincter involvement [Figure 1]. Involvement of internal anal sphincter (IAS) alone was the most common sphincter involvement followed by the involvement of all three sphincters together (IAS and external anal sphincter and longitudinal muscle) [Figure 1].

Iliac lymph nodes involvement was found in 11 patients $(14.5 \%)$ while presacral lymph nodes were involved only in $2.6 \%$ of patients ( 2 cases).

\section{Discussion}

This study showed that more than half of rectal cancers $(55.3 \%)$ occur in the distal section of rectum. In addition, advanced

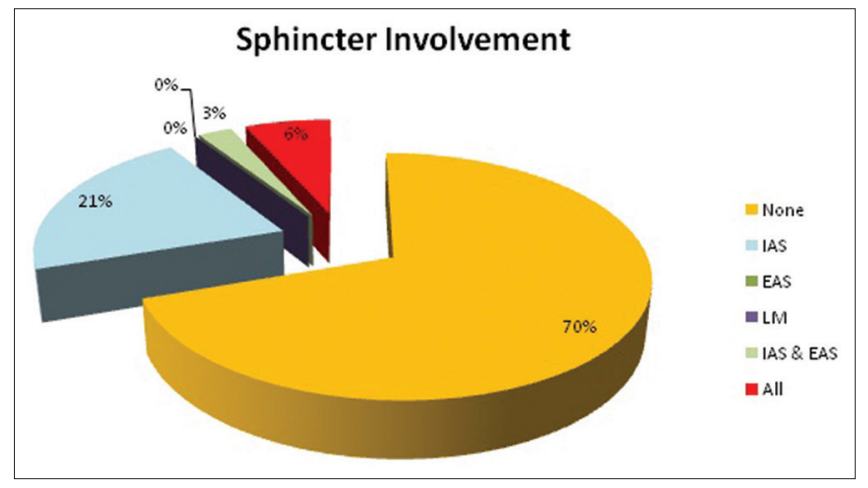

Figure 1: Frequency of different anal sphincters involvement in patients with rectal cancer. IAS: Internal anal sphincter, EAS: External anal sphincter, LM: Longitudinal muscle 
tumor size (T3) was found in more than $65 \%$ of patients and lymph node involvement was identified in more than $70 \%$ of patients at diagnosis. About $58 \%$ of patients were male and $42 \%$ were female.

Overall CRC accounts for 9\% of cancer death worldwide. According to the WHO report, about $60 \%$ of CRC occurs in developed countries, but the incidence and mortality of CRC in these countries have decreased slowly with a rate of $2-3 \%$ per year in men and women over the past 15 years. ${ }^{[3,5]}$ Despite this status in developed world, it is estimated that the rate of CRC incidence to increase over the next decade in developing world including Asian countries. ${ }^{[7]}$

In addition, low socioeconomic status in these countries increases the risk of CRC incidence and death. ${ }^{[8,9]}$

$\mathrm{CRC}$ is a disease of aging and the average age at diagnosis is about 70 years. $^{[10]}$ This issue is important because our population is aging and it is expected that the number of new cases to rise dramatically with the aging of the population. ${ }^{[1]}$ Our population is at greater risk for the development of CRC because the risk of CRC incidence among young people (age $\leq 40$ years) in the Middle East countries like ours is about $15-35 \%$ while it is $2-8 \%$ in Western countries ${ }^{[12]}$ and also because most of our population is young ( $<40$ years). These two factors may put our population at higher risk for CRC incidence.

It has been shown that in regions with low incidence of CRC such as Middle East countries (Pakistan and Iran...), development of CRC in distal colon and rectum is more likely while in high incidence countries it is more likely to be located in the proximal colon. ${ }^{[13]}$

Rectal cancer is also a disease of old age with a mean age of 65 years at the time of diagnosis which is lower than that for colon cancer. ${ }^{[14,15]}$ In our study, the median age at diagnosis of rectal cancer was 57 years in men and 56 years in women which is less than that reported previously (63 years in men and 65 years in women) and in our study it was lower in women than in the men while it was reported higher in women. ${ }^{[14]}$

Tumor location varies by age and rectal tumors significantly decrease in older age. In our study, $80 \%$ of rectal cancers occurred in the distal part of rectum in age $>65$.

In a similar study by Elmernissi et al. in Morocco in 2009, 232 patients with rectal cancer were evaluated. ${ }^{[16]}$ The number of patients in that study was higher than in ours. The mean age of patients in that study was $52.8 \pm 15.4$ years, which is less than those of our patients are. In that study, $25.9 \%$ of patients were below 40 years of age and $60 \%$ of them were male. In addition, the involvement of lower rectum was observed in $43.5 \%$ of patients in Elmernissi et al. study, which is less than in our patients $(55.3 \%)$. The main difference of our study with
Morocco study is that we evaluated the patients at diagnosis, but they assessed all patients and their treatment. ${ }^{[16]}$

In Zahir et al. study in 2014, clinical features of CRC was reported in 131 patients in Pakistan. ${ }^{[17]}$ In that study, $45 \%$ of cases were rectal cancer and the mean age of patients with rectal carcinoma was $32.80 \pm 8.0$ years, which is lower than in our patients. In their study, $62.7 \%$ of patients with rectal cancer were male that is near to our study. ${ }^{[17]}$ Intestinal obstruction was the main symptom in $13.6 \%$ of patients with rectal cancer in that study which similar to our finding (14.5\%).

Lack of assessment of symptoms at presentation, tumor histology, treatment, outcome, and survival are the main limitations of our study.

Future studies with greater sample size and including all CRC cases with a collection of all required data from different aspects is suggested to depict endosonographic feature of colon and rectal cancers perfectly.

\section{Conclusion}

The mean age at diagnosis of rectal cancer in our country is less than that in Western countries but still more than $50 \%$ of our patients are middle-aged. Lower rectum is the most common location of rectal cancer in our patients. It seems that our patients refer late in the course of disease because local lymph node metastasis was present in more than $70 \%$ of our patients at the time of diagnosis.

\section{Financial support and sponsorship}

Nil.

\section{Conflicts of interest}

There are no conflicts of interest.

\section{References}

1. Ferlay J, Soerjomataram I, Dikshit R, Eser S, Mathers C, Rebelo M, et al. Cancer incidence and mortality worldwide: Sources, methods and major patterns in GLOBOCAN 2012. Int J Cancer 2015;136:E359-86.

2. Hoseini S, Moaddabshoar L, Hemati S, Mohammadianpanah M. An overview of clinical and pathological characteristics and survival rate of colorectal cancer in Iran. Ann Colorectal Res 2014;2:e17264.

3. Rezaianzadeh A, Safarpour AR, Marzban M, Mohaghegh A. A systematic review over the incidence of colorectal cancer in Iran. Ann Colorectal Res 2015;3:e25724.

4. Fritz A, Percy C, Jack A, Shanmugaratnam K, Sobin L, Parkin DM, et al., editors. International Classification of Diseases for Oncology. $3^{\text {rd }}$ ed. Geneva: World Health Organization; 2000.

5. Siegel R, Desantis C, Jemal A. Colorectal cancer statistics, 2014. CA Cancer J Clin 2014;64:104-17.

6. Benson AB $3^{\text {rd }}$, Venook AP, Bekaii-Saab T, Chan E, Chen YJ, Cooper HS, et al. Rectal cancer, version 2.2015. J Natl Compr Canc Netw 2015;13:719-28.

7. Ferlay J, Shin HR, Bray F, Forman D, Mathers C, Parkin DM. Estimates of worldwide burden of cancer in 2008: GLOBOCAN 2008. Int J Cancer 2010;127:2893-917. 
8. Doubeni CA, Laiyemo AO, Major JM, Schootman M, Lian M, Park Y, et al. Socioeconomic status and the risk of colorectal cancer: An analysis of more than a half million adults in the National Institutes of Health - AARP diet and health study. Cancer 2012;118:3636-44.

9. Albano JD, Ward E, Jemal A, Anderson R, Cokkinides VE, Murray T, et al. Cancer mortality in the United States by education level and race. J Natl Cancer Inst 2007;99:1384-94.

10. Boyle P, Leon ME. Epidemiology of colorectal cancer. Br Med Bull 2002;64:1-25.

11. United Nations. World Population Ageing: 1950-2050. New York: United Nations Publications; 2002.

12. Ansari R, Mahdavinia M, Sadjadi A, Nouraie M, Kamangar F, Bishehsari F, et al. Incidence and age distribution of colorectal cancer in Iran: Results of a population-based cancer registry. Cancer Lett 2006;240:143-7.

13. Goh KL, Quek KF, Yeo GT, Hilmi IN, Lee CK, Hasnida N, et al.
Colorectal cancer in Asians: A demographic and anatomic survey in Malaysian patients undergoing colonoscopy. Aliment Pharmacol Ther 2005;22:859-64.

14. Howlader N, Noone AM, Krapcho M, Garshell J, Neyman N, Altekruse SF, et al., editors. Seer cancer statistics review, 1975-2010. ed. Bethesda, MD: National Cancer Institute; 2013.

15. El Mernissi H, Hrora A, Mrini K, Benamer A, Sebbah F, Raiss M, et al. Rectal cancer on young patient compared with elderly patient about a moroccan hospital service experience. Arab J Gastroenterol 2009;10:29.

16. Elmernissi H, Hrora A, Mrini K, Benamer A, Raiss M, Sebbah F, et al. Epidemiologic characteristics of rectal cancers: About 232 cases in a moroccan hospital unit. Arab Journal of Gastroenterology 2009;10:AB27-35.

17. Zahir MN, Azhar EM, Rafiq S, Ghias K, Shabbir-Moosajee M. Clinical features and outcome of sporadic colorectal carcinoma in young patients: A cross-sectional analysis from a developing country. ISRN Oncol 2014;2014:461570. 